\title{
Türkçe ve Almanca Dijital Ortamlarda Kadınların Kullandıkları Hitap İfadeleri ${ }^{1}$
}

\author{
Fatma Öztürk Dağabakan (D), Erzurum
}

https://doi.org/10.37583/diyalog. 1030753

$\ddot{O} z$

Hitaplar gerek formal konuşmada gerekse informal dilde belirleyici bir özelliğe sahiptir. Hitaplar konuşmaya, yazmaya veya herhangi bir yazılı belgeye başlarken kullanılan ve göndericinin alıcıya yönelik bakış açısını belirten dilsel ifadelerdir. Hitap edilen kişi veya gruplar muhatap olarak adlandırılır.

Selamlama ve hitap araştırmalarında, bir muhataba hitap ederken kullanılan dilsel araçlara hitap biçimleri denir. Dilsel hitap biçimleri, ad ve zamir kategorisine ayrılabilir. Ad kategorisindeki hitap türleri isimlerin, mesleki ve diğer unvanların kullanımını içerir. Hitapların zamir biçimleri kendilerini şahıs zamirlerinde gösterir. Zamirlerin bir alt sınıfı olarak, şahıs zamirleri gönderene veya kişilere atıfta bulunur.

Dilsel iletişim hitaplar ile başlar. Herhangi bir konu hakkında birisiyle birdenbire konuşmaya başlamamak toplumsal uzlaşımın bir parçasıdır. Bu bağlamda hitaplar yaşamın her anında yer bulmaktadır.

$\mathrm{Bu}$ makalede, Türk ve Alman dijital ortamlarda kadınların hitap ifadelerinin incelenmesi amaçlanmaktadır. İnternet günümüzde toplumun her alanındaki insanların zorunlu bir alışkanlığı haline gelmiştir. Toplumdaki bireyler etkileşimlerini büyük oranda internet aracılığı ile gerçekleştirmekte, sosyal medyayı takip ederek merak ettikleri konular hakkında fikir sahibi olabilmektedirler. Toplumda, arasında kadınların da önemli bir yere sahip olduğu büyük bir kesim günün her anında sosyal medya üzerinden iletişim kurmakta, kurdukları her tür iletişimde farklı hitap türleri sergilemektedir. Bu çalışma, kullandıkları hitaplar açısından kadınların dilsel davranışlarını içermektedir. Bilindiği gibi kadınlar ve erkekler birçok açıdan ayrıdırlar. Kadın ve erkekler arasındaki bu farklılıklar kendine dijital ortamda da yer bulmaktadır.

Makalenin birinci bölümünü oluşturan kuramsal kısımda, hitapların tanımından yola çıkılarak konunun ayrıntıları ortaya konacaktır. Çalışmanın uygulama bölümünde, Türkçe ve Almancadaki sosyal medya metinleri her iki dilde hitaplar açısından karşılaştırılarak incelenecektir. Elde edilen veriler kadınların iki dildeki hitap kullanımı bağlamında değerlendirilecektir. Bu değerlendirme sonucunda Türkçe ve Almancada kadın dilinin hitaplar açısından nasıl bir kullanım alanının olduğu görülecek, her iki dilde ne tür farklılıklar ve benzerliklerin gözlemlenebildiği sonucuna ulaşılacaktır.

Çalışmada Türkçe ve Almanca hitaplar karşılaştırılacağından inceleme genel olarak kontrastif söylem analizi ve deskriptif-analitik yöntemler doğrultusunda karma bir yöntem ile yürütülecektir.

Anahtar Sözcükler: Hitaplar, Kadın dili, Toplumdilbilim, Sosyal medya, Türkçe-Almanca.

Einsendedatum: 14.10.2021

Freigabe zur Veröffentlichung: 01.12.2021

${ }^{1} \mathrm{Bu}$ çalışma Atatürk Üniversitesi BAP Koordinasyon Birimi tarafından desteklenen SUA-2019-7136 nolu “Türkiye'de ve Almanya'da Kadın Dili” başlıklı Uluslararası Bilimsel Araştırma İş birliği Projesi kapsamında, Berlin Humboldt Üniversitesinde Prof. Dr. Ulrike VEDDER danışmanlığında gerçekleştirilerek Edirne "XV. Internationaler Türkischer Germanistik Kongress” adlı kongrede sunulan "Türkçe ve Almanca Dijital Ortamda Kadınların Kullandıkları Hitap İfadeleri” başlıklı bildirinin genişletilmiş, ve gözden geçirilmiş halidir. 


\section{Abstract}

\section{Adress Terms Used By Women In Turkish And German Digital Environments}

Salutations act as a defining feature in both daily speech and official language. Salutations are linguistic expressions used when beginning to speak, write or as an opening line in any written document. They indicate the sender's point of view towards the receiver. The people or groups addressed are called the addressee.

In salutations and addresses research, the linguistic tools used when addressing an interlocutor are called forms of address. Linguistic forms of address can be divided into the categories of nouns and pronouns. The types of addresses in the name category include names, professional and other titles. The pronoun forms of the addresses are expressed as the pronouns of an individual. As a subclass of pronouns, personal pronouns refer to the sender or the addressed persons. Linguistic communication begins with addresses. It is part of social convention not to suddenly start talking to someone about any subject. In this context, addresses find a place in every moment of life.

This article aims to examine the addressing expressions of women in Turkish and German digital environments. Internet has become a compulsory habit of people in all walks of life for today's society. Individuals carry out their social interactions mostly through the internet, deriving their ideas about the topics of interest by following social media. A large part of the society, in which women have an important place, communicates through social media at every moment of time and display different types of address in every communication they establish. This study includes the linguistic behavior of women in terms of the addresses they use. As is known, men and women are different in many respects. These differences between men and women also find their place in the digital environment.

In the theoretical part, which constitutes the first part of the article, the details of the subject will be examined based on the definition of addresses. In the application part of the study, social media texts in Turkish and German will be compared in terms of addresses in both languages. The data obtained will be evaluated in the context of women's bilingual use of addresses. As a result of this evaluation, the area of use of the female language in terms of addresses in Turkish and German will be shown, conclusion will be reached regarding the kind of differences and similarities that can be observed in both languages.

Since Turkish and German addresses will be compared in the study, the examination will be carried out with a mixed method approach in line with contrastive discourse analysis and general descriptiveanalytical methods.

Keywords: Addresses, Women's language, Sociolinguistics, Social media, Turkish-German. 


\section{EXTENDED ABSTRACT}

Salutations act as a defining feature in both daily speech and official language. Salutations are linguistic expressions used when beginning to speak, write or as an opening line in any written document. They indicate the sender's point of view towards the receiver. The people or groups addressed are called the addressee.

Linguistic communication begins with addresses. It is part of social convention not to suddenly start talking to someone about any subject. In this context, addresses find a place in every moment of life.

During communication, the sender and receiver call out to someone in different ways for different purposes or reasons. In his article, Fatih Doğru (2018: 135), states that calling, warning, attracting attention, activating, showing sincerity and formality, showing status, honoring, controlling communication, showing that you are in communication, excitement, joy, love, respect, hate, reflecting various emotions such as fear, sadness, anger, insulting, humiliating, mocking, reproaching, asking for help, scolding, begging, threatening, etc. emphasizes that it takes place in different ways depending on variables such as culture, gender, age, sincerity, type of sender and addressee for various purposes or reasons. Doğru states that the words spoken or written by someone in this way in line with some of their characteristics are defined as addressing words (2018: 135-136).

In salutations and addressing studies, the linguistic tools used for addressing an interlocutor are called addressing forms. Linguistic forms of address can be divided into the categories of nouns and pronouns. The types of addresses in the name category include names, professional and other titles, expressions of love, respect, and kinship concepts. Pronoun forms of addresses manifest themselves in personal pronouns and refer to the sender or the person addressed in the context of personal or social distance.

In this study, a gender-oriented approach will be implemented as the study includes the linguistic behaviors of women in terms of the addresses they use. With this study, it is aimed to examine the reflections of the addresses used by women in the digital environment.

As is known, there are many differences between men and women. We see reflection of these differences in language. The differences between the language used by women and men are now being studied in sociolinguistics as well as in different other fields, and research on this subject, which is more recent, continues to draw attention of academia. Women's language with its own characteristics is a way of speaking employed by women. It is one of the variables that make up the language as a whole. While women's language reveals the structural differences of women, it also reflects the effects of the roles that women have assumed socially (Öztürk Dağabakan 2016: 41-42).

Internet has become a compulsory habit of people in all walks of society today. Individuals in the society carry out their interactions mostly through the internet, and they can have an idea about the subjects they are curious about by following the social media. A large part of the society, among which women have an important place, communicate through social media at every moment of the day and display different types of address in every communication they establish. This study includes the linguistic behavior of women in terms of the addresses they use. As is known, men and women are different in many respects. These differences between men and women also find their place in the digital environment. This extraordinary period, in which the pandemic affects our entire lives, without the possibility to predict how long it will last, has also become an element that requires and even necessitates digitalization of communication. 
In the theoretical part, which constitutes the first part of the article, the details of the subject will be examined based on the definition of addresses. In the application part of the study, social media texts in Turkish and German will be compared in terms of addresses in both languages. The data obtained will be evaluated in the context of women's bilingual use of address. As a result of this evaluation, the area of use of the female language has in terms of addresses in Turkish and German will be shown, conclusion will be reached regarding the kind of differences and similarities that can be observed in both languages.

Since Turkish and German discourses will be compared in the study, the examination will be carried out with a mixed method in the context of contrastive discourse analysis in general. The said mixed method developed in line with the descriptive-analytical method will follow the following steps:

1. Theoretical definition of addresses,

2. Collection of German and Turkish linguistic material from the discourses encountered on digital platforms (WhatsApp, SMS, Mail, Messenger, etc.),

3. In-language examination of the structural and semantic properties of the collected data,

comparative analysis of the findings. 


\section{Giriş}

Hitaplar gerek formal konuşmada gerekse informal dilde belirleyici bir özelliğe sahiptir. Hitaplar konuşmaya, yazmaya veya herhangi bir yazılı belgeye başlarken kullanılan ve göndericinin alıcıya yönelik bakış açısını belirten dilsel ifadelerdir. Hitap edilen kişi veya gruplar muhatap olarak adlandırılır.

Dilsel iletişim hitaplar ile başlar. Herhangi bir konu hakkında birisiyle birdenbire konuşmaya başlamamak toplumsal uzlaşımın bir parçasıdır. Bu bağlamda hitaplar yaşamın her anında yer bulmaktadır.

İletişim esnasında gönderici ve alıcı farklı amaç veya sebeple, farklı şekillerde birilerine seslenirler. Fatih Doğru (2018: 135), makalesinde, kişiler ve gruplar arası seslenmelerin, "çağırma, uyarma, dikkat çekme, harekete geçirme, samimiyet ve resmiyet gösterme, statü gösterme, onurlandırma, iletişimi kontrol etme, iletişimde olduğunu gösterme, heyecan, sevinç, sevgi, saygı, nefret, korku, üzüntü, kızgınlık gibi çeşitli duyguları yansıtma, hakaret etme, aşağılama, alay etme, sitem etme, yardım isteme, azarlama, yalvarma, tehdit etme vb. çeşitli amaç ya da sebeplerle içinde bulunulan kültür, cinsiyet, yaş, samimiyet, seslenen ve seslenilenin türü gibi değişkenlere bağlı olarak farklı şekillerde" gerçekleştiğini vurgulamaktadır. Doğru, bu şekilde birilerine, onların birtakım özellikleri doğrultusunda yöneltilerek söylenen veya yazılan sözlerin, seslenme sözleri yani hitaplar olarak tanımlandığını belirtmektedir (2018: 135-136).

$\mathrm{Bu}$ makalede, Türk ve Alman dijital ortamlarda kadınların hitap ifadelerinin incelenmesi amaçlanmaktadır. Dil ve cinsiyet ikilisinin dilbilimde her açıdan araştırıldığ görülmektedir. Ancak beraber "toplumdilbilimsel bir değişken olarak kadın dili araştırmalarına 20. yüzyılda ağırlık verilmeye" başlanmıştır (Öztürk Dağabakan 2016: 42). Son yıllarda ise bu tarz araştırmaların sayısı oldukça artmıştır. Kadın dilinin, kadınların gönderen ve alıcı olarak hitap kullanımları bağlamında araştırıldığı bilimsel yayınlar bulunmakla beraber (Yıldırım 2017; Wieczorek 2014), (Han / Elkılıç / Aybirdi 2019; Aça 2018) kadınların Türkçe ve Almanca dijital ortamlarda kullandığı hitapların ele alınmış olduğu çalışmalara rastlanmamaktadır. Söz konusu çalışmalara kısaca değinmek gerekirse: Nilüfer Yıldırım'ın kaleme almış olduğu "Çağdaş Türk Yazı Dillerinde Kadına Yönelik Hitaplar” adlı makalede yazı dillerinde kadınlara yönelik hitap ifadeleri incelenmektedir (Yıldırım 2017). Marianne Wieczorek tarafından yazılmış olan "SMS-Kommunikation von Männern und Frauen am Beispiel von Begrüßungs- und Verabschiedungsformeln" adlı çalışmada SMS iletişiminde kadınların ve erkeklerin kullandığı selam ve veda ifadeleri kontrastif bir inceleme bağlamında değerlendirilmekte, makalede hitap ifadeleri ele alınmamaktadır (Wieczorek 2014). Turgay Han, Gencer Elkılıç, ve Nilüfer Aybirdi'nin birlikte yayınladıkları "Eşlerin Birbirlerine Sosyo-Edimsel Hitap Biçimleri Üzerine Tanımlayıcı Bir Çalışma" (Han/ Elkılıç/ Aybirdi 2019), başlıklı yazıda eşlerin birbirlerine hitapları edimbilimsel bir yaklaşım açısından değerlendirilmekte, söz konusu makalede kadınların eşlerine karşı kullandıkları hitap ifadelerine yöresel bazda değinilmektedir. Mustafa Aça'nın yazmış olduğu "Balıkesir Yöresinde Eşlerin Birbirlerine Hitap Biçimlerinin Bir Türü Üzerine” (2018) başlıklı makalede ise yine bir önceki çalışmada olduğu gibi eşlerin birbirlerine karşı kullandıkları 
hitap ifadeleri yöresel bağlamda incelemektedir. Görüldüğü gibi bu çalışmanın konusunu oluşturan, kadınların Türkçe ve Almanca dijital ortamlarda kullandığı hitaplar, henüz yeterince araştırılmamıştır. Dolayısıyla çalışma alanda önemli bir boşluğu dolduracağı ve yeni araştırmalara yön vereceği düşünülmektedir.

İnternet günümüzde toplumun her alanındaki insanların zorunlu bir alışkanlığı haline gelmiştir. Toplumdaki bireyler etkileşimlerini büyük oranda internet aracılığı ile gerçekleştirmekte, sosyal medyayı takip ederek merak ettikleri konular hakkında fikir sahibi olabilmektedirler. Toplumda, arasında kadınların da önemli bir yere sahip olduğu büyük bir kesim günün her anında sosyal medya üzerinden iletişim kurmakta, kurdukları her tür iletişimde farklı hitap türleri sergilemektedir. Pandeminin tüm yaşantımıza etki ettiği halihazırda içinde bulunduğumuz ve daha ne kadar süreceği hakkında bir fikir sahibi olmadığımız bu olağanüstü dönem de iletişimde dijitalleşmeyi gerektiren hatta zorunlu kılan bir unsur olmuştur.

Makalenin birinci bölümünü oluşturan kuramsal kısımda, hitapların tanımından yola çıkılarak konunun ayrıntıları ortaya konacaktır. Çalışmanın uygulama bölümünde, Türkçe ve Almancadaki sosyal medya metinleri her iki dilde hitaplar açısından karşılaştırılarak incelenecektir. Elde edilen veriler kadınların iki dildeki hitap kullanımı bağlamında değerlendirilecektir. Bu değerlendirme sonucunda Türkçe ve Almancada kadın dilinin hitaplar açısından nasıl bir kullanım alanının olduğu görülecek, her iki dilde ne tür farklılıklar ve benzerliklerin gözlemlenebildiği sonucuna ulaşılacaktır.

Çalışmada Türkçe ve Almanca söylemler karşılaştırılacağından, incelemede genel olarak kontrastif söylem analizi bağlamında nitel ve nicel verilerin ele alınacağı karma bir yöntem kullanılacaktır. Söz konusu karma yöntem deskriptif-analitik yöntem doğrultusunda gelişerek, hitapların kuramsal tanımı, anket, gözlem ve görüşme yoluyla elde edilen verilerin, aynı zamanda dijital platformlarda (WhatsApp, SMS, Mail, Messenger vb.) karşılaşılan söylemlerden derlenen materyalin yapısal ve anlamsal özelliklerinin dil içi incelenmesi, bulguların karşılaştırmalı analizi doğrultusunda gerçekleştirilecektir.

\section{Hitaplar}

Hitap ifadeleri iletişimi başlatan dilsel öğelerdir. Toplumsal uzlaşım, birisiyle iletişim kurarken birdenbire konuşmaya başlamamayı gerektirmektedir. Bu yüzden hayatın her alanında ve her anında hitap ifadeleri kullanılmaktadır.

Türk Dil Kurumu Sözlüğünde "sözü birine veya birilerine yöneltme, seslenme” (Akalın 2011: 1106) olarak tanımlanan hitaplar gerek günlük konuşmada gerekse resmi dilde belirleyici bir özelliğe sahiptir. İletişim kurulan kişi, grup veya topluluklara atıfta bulunmayı sağlayan hitaplar iletişim kuran bireyler arasındaki ilişkileri destekler. Söz konusu bu ilişkiler ortaya koyduğu özellikler bağlamında hitaplar vasıtasıyla belirginleşir. Yani hitaplar yoluyla dilsel göstergeler ile dil dışı bir gerçekliğe göndermede bulunulmaktadır. Konuşmaya, yazmaya veya herhangi bir yazılı belgeye başlarken kullanılan hitaplar göndericinin alıcıya yönelik bakış açısını belirten dilsel 
ifadelerdir. Hitaplar yoluyla iletişim kuran bireyler arasındaki ilişki düzeyi ortaya çıkar. $\mathrm{Bu}$ seviye birçok düzlemde değerlendirilmektedir. Bunlar arasında en önemlilerinden birisi kültür olgusu olarak karşımıza çıkmaktadır. Kültüre bağlı olarak yaş, cinsiyet, konum, meslek, durum gibi birçok etken de hitap eyleminde önemli bir yere sahiptir.

Hitaplar üzerine yapılan toplumdilbilimsel araştırmalar sonucunda hitaplara ilişskin bir dizi evrensel kural ortaya çıkmıştır. Bu bağlamda hitap tercihlerindeki farklılıkların iki boyutta değerlendirildiği görülmektedir. Hitapların kullanımı hem dikey bir statü hiyerarşisi hem de yatay bir dayanışma veya yakınlık boyutu gerektirmektedir (Bußmann 2008: 44).

Toplum bireyleri iletişim kurdukları insanlar ve gruplara genel olarak sosyal statülerine göre hitap ederler. Söz konusu bu sosyal statü toplumun her bireyi için her durumda farklılıklar gösterebilir. Bir yerde yüksek bir statüye sahip olan bir birey, başka bir durumda daha farklı bir ortamda alt bir statüde gözlemlenebilir. Yani bir yerde müdür, işveren, akademisyen vb. gibi bir makama sahip olan birey başka bir ortamda bir arkadaş, bir anne veya baba, kardeş, evlat, komşu vb. birçok statü içerisinde tanımlanabilir. Ebeveyni karşısında alt statüde yer alan kişiyi, çocuklarına karşı üst statüde konumlandırmak mümkündür. Yine statü açısından bakıldığında her bir ortamda statüler de değişebilmektedir. Toplumsal statüler arasında hiyerarşik bir yapı vardır (Ceylan 2012: 93) ve hitaplarda da bu yap1 görülmektedir. Bu yapıda konumlanan hitap farklılıkları hiyerarşik farklılıkları yansıtan dikey boyut bağlamında tanımlanmaktadır. Dikey boyut hitaplarda hiyerarşik farklılıkları yansıtır ve çoğunlukla resmi hitap türleri bu grup içerisinde değerlendirilir.

Toplumdilbilimsel araştırmalar sonucunda tanımlanan bir diğer boyut olarak karşımıza çıkan yatay boyutta dayanışma ve samimiyet duygusu hitap biçimlerini belirlemektedir. Bu hitap biçimlerinde resmi olan hiyerarşik yapıdan ziyade öznel bir yaklaşım görülmektedir. Bireylerin kendileri ile sosyal olarak aynı seviyede olan kişiler veya topluluklarla iletişime başlarken kullandıkları hitap ifadelerini bu boyutta değerlendirmek mümkündür. Söz konusu hitap ifadeleri daha samimi ve duygusal, daha doğrusu kişisel bir özellik sergilemektedir.

Dilsel iletişim hitaplar ile başlar ve insanlar arasındaki ilk temas da hitaplar yoluyla gerçekleşir. Bu yüzden hitaplar bir dildeki en önemli dilsel eylemlerden birisi olma özelliğini taşır. Doğru hitap etme bilgisi, toplum içerisindeki başarılı iletişimin nedenidir. Bu nedenle, uygun hitap biçimini seçmek özellikle önemlidir (Spillner 2001: 10-12). Bernd Spillner, başarılı bir iletişim kurulması için gerekli olan doğru hitap biçimlerinin özelliklerini hitapların edimbilimsel yönleri bağlamında sıralamaktadır. Ona göre kişilerarası iletişim için doğru hitap ifadelerinin kullanımı çok önemlidir. Söz konusu hitap seçimi tüm hitap biçimlerine eşlik eden durumsal eylemden kolayca çıkarılabilir. Spillner, hitapların her zaman iletişimsel sosyal ilişkinin başında yer alarak ilk temasla, genellikle ilk kişisel algıyla bağlantılı olduğunu, aynı zamanda sosyal bir ilişkiye sözlü girişi aksiliklerle yüklememenin, onu olumlu bir şekilde şekillendirmek için doğru hitap biçimini seçmenin çok önemli olduğunu vurgulamaktadır (Spillner 2014: 174-176). İlk temas buna bağlı olarak ilk hitap iletişim kurarken önemli bir yere sahiptir. 
Sosyal ilişkiye girerken kullanılan yanlış bir hitap ifadesi ilişkinin kurulamamasına, kurulan ilişkinin bozulmasına hatta kopmasına neden olmaktadır.

Hitapların özelliklerini edimbilimsel bir yaklaşımla ele alan Spillner, hitapların toplumsal gelenek bağlamında önemine değinmektedir. Birisiyle herhangi bir konu hakkında birdenbire konuşmaya başlamamak toplumsal geleneklerin bir parçasıdır. Önce kimin kiminle konuştuğunun bilinmesi gerekir. Bu yüzden iletişim kuran bireylerin geleneksel olarak belirlenmiş şekilde tanışması gerekmektedir. Sözlü ve aynı zamanda yazılı hitap biçimleri, dilsel iletişimi başlatmada önemli bir ilk adımdır. Hitaplar yoluyla iletişim kuran bireyler arasında aynı zamanda sosyal bir ilişki oluşturulmakla beraber sosyal bir hiyerarşi düzeni kurulmuş daha da ötesi kararlaştırılmış olur. Hitap edilen kişi hitap ifadesiyle bile belirli bir sosyal gruba atanır. Böylece hitap biçimleri iletişim kuran bireylerin sosyal konumlarını dilsel olarak tanımlamaya katkıda bulunur, bununla beraber iletişim kurulan kişiye yönelik dikkat ve ilgiyi ifade eder (Spillner 2014: 174-176).

Spillner'in vurgulamış olduğu hitap özellikleri toplumsal iletişim bağlamında değerlendirildiğinde iletişimin sağlıklı olması bakımından tür toplumlar için geçerlilik sağlamaktadır. Seçilen hitap ifadesi yalnızca hitap edilen kişiye verilen değeri göstermekle kalmaz, aynı zamanda hitap eden kişi hakkında da bilgi sağlar, onun dilsel normları tanıdığını, kabullendiğini ve bu normlara saygı duyduğunu gösterir. Bu nedenle, doğru bir hitap, onu formüle edenler için aynı zamanda bir sosyal kartvizittir (Spillner 2014: 174-176).

Selamlama ve hitap araştırmalarında, bir muhataba hitap ederken kullanılan dilsel araçlara hitap biçimleri denir. Dilsel hitap biçimleri, ad ve zamir kategorisinde yer bulurlar. Ad kategorisindeki hitap türleri özel isimler, mesleki ve diğer unvanlar, sevgi saygı ifadeleri, akrabalık kavramları gibi tanımların kullanımını içerir. Bu tür hitap biçimleri genellikle ikinci bir kişiye karşılık gelen ve vokatif (hitap halleri) (Johnen 2019: 11) olarak kullanılan ad biçimleri olarak tanımlanır.

Hitapların zamir biçimleri kendilerini şahıs zamirlerinde gösterir ve gönderene veya hitap edilen kişiye kişisel veya sosyal mesafe bağlamında atıfta bulunur.

Zamir türünden olan hitap biçimleri, daha soyut olmaları nedeniyle, isim türünden olanlardan anlamsal olarak farklıdır. Bunlar esasen kişisel gönderge (muhatap alınan kişinin tanımı) ve sosyal gönderge (konuşmacı ile hitap edilen kişi arasındaki sosyal mesafe: sen ve siz arasındaki fark gibi) ile sınırlıdır. Bununla birlikte, isim türünden olan hitap biçimleri bu iki gönderim biçimiyle sınırlı değildir. İsim türü hitap biçimleri ayrıca hitap edilen kişiyi tanımlayıp karakterize etme işlevi de gösterirler. Bu durumda, isim hitap biçimleri, zamir hitap biçimlerinden farklılık gösterir (Johnen 2019: 11).

Hitap edilen kişi veya gruplar muhatap olarak tanımlanmaktadır. Kişisel hitaplar için çeşitli dillerde farklı şekilde dile getirilen ifade birikiminin tümü hitap şekillerini oluşturur (Bußmann 2008: 44). Hitaplardaki statü benzerliklerine ve farklılıklarına bağlı olarak kullanılan hitap biçimleri de içeriksel ve şekilsel farklılıklar düzleminde sınıflandırılmaktadır. Nilüfer Yıldırım, "Dilin zenginliğini, sözcüklerin farklı anlamlar yüklenecek şekilde kullanımını, milleti oluşturan bireylerin dili etkili kullanma yetisini 
gözler önüne seren" hitapların, "hitap edilen kişinin yaşına, konumuna, cinsiyetine, mesleğine ve seslenme amacına göre değişiklik" gösterdiğini vurgulamaktadır. (Yıldırım 2017: 124). Aynı zamanda hitap eden kişinin de yaşı, toplumsal konumu, cinsiyeti, mesleği ve seslenme amacına göre hitaplar farklılık göstermektedir.

$\mathrm{Bu}$ çalışmada cinsiyet odaklı bir yaklaşım söz konusu olacaktır ve çalışma, kadınların kullandıkları hitaplar açısından dilsel davranışlarını içermektedir. Bu çalışma ile kadınların kullandıkları hitapların dijital ortamdaki yansımalarının incelenmesi amaçlanmaktadır.

Bilindiği gibi kadınlarla erkekler arasında birçok ayrılık bulunmaktadır. Bu farklı1ıklardan birini de dilde görmekteyiz. Kadınlar ve erkeklerin kullandıkları dil arasındaki farklılıklar günümüzde farklı alanların yanı sıra toplumdilbilimde de incelenmektedir ve daha çok yeni olan bu konu üzerine yapılan araştırmalar dikkatleri çekmektedir. Kadın dili ile toplumda konuşulan dilden başka bir dil anlaşılmamalıdır. Kadın dili, kadınların konuştuğu, kendine has özellikleri olan bir konuşma biçimidir ve dili oluşturan değişkenlerden birisidir. Kadın dili, kadınların yapısal farklılıklarını ortaya koymakla beraber, kadınların toplumsal olarak üstlenmiş oldukları rollerin etkilerini de barındırmaktadır (Öztürk Dağabakan 2016: 41-42). Söz konusu toplumsal rollerin hitaplar açısından dijital ortamdaki yansımaları bu çalışmada ele alınacaktır.

\section{Türkçe ve Almanca Dijital Ortamda Kadınların Kullandıkları Hitap İfadeleri}

İnternet günümüzde toplumdaki herkesin vazgeçilmez bir alışkanlığı hatta alışkanlıktan öte bir zorunluluğu haline gelmiştir. Toplumdaki bireyler genelde birçok işlerini internet yoluyla halletmektedirler. İçinde bulunduğumuz pandemi dönemi de bu konuda pekiştirici bir etki göstermiştir. Önceden yüz yüze yaptığımız dersler pandemi ile online bir özellik kazanmıştır. Sadece dersler değil, alışverişler, ödemeler kısacası günlük hayatın her bir eylemine dijital süreçte bir karşılık bulur olduk. Kültürümüzü yansıtan gelenek ve görenekler bile dijital ortamda yansımasını buldu. Kız istemeler, düğün törenleri, iftar yemekleri ve diğerleri bunlardan bazıları olarak sıralanabilir.

Toplumsal iletişim de büyük oranda dijitalleşme sürecinden nasibini almış bulunmakta. Her türlü iletişim dijital ortamda gerçekleştirilmekte, sosyal medya takibi ile bireylerin merak ettikleri konular açıklığa kavuşmaktadır.

Toplumun büyük bir kesimi her an sosyal medya üzerinden iletişim kurmaktadır. Sosyal medyada kullanılan dijital platformlar hem bir iletişim hem de aynı zamanda paylaşım aracı olarak insanların günlük hayatlarında vazgeçilmez bir unsur olmuştur. Bu bağlamda bireyler dijital platformlarda özel bir dil oluşturmuş, bu dil ile karşı tarafla farklı bir etkileşim kurma yoluna girmiştir. "Sosyal medya, kullanıcıların birbiriyle etkileşimini ve medya içeriğini bireysel veya toplumsal bazda tasarlamalarını sağlayan dijital medya ve teknolojilerin çeşitliliğidir." (Naber 2015: 2).

Sosyal medya, içeriğinin çoğunlukla kullanıcıları tarafından belirlendiği online hizmetlerin bütünü olarak açıklanmaktadır. Söz konusu bu hizmetlerin temelini çoğunlukla bilgi alışverişi ve iletişim oluşturmaktadır. Dijital platformları kullanan 
bireyler arasındaki etkileşim karş1lıklı bilgi, düşünce, fikir, izlenim ve içerik oluşturmada birlikte hareket bağlamında gerçekleşmektedir. Günümüz toplumu teknolojiyi takip ettiği ve toplumsal yapı da teknolojiye paralel bir şekilde hızla gelişip değişime uğradığı için toplumda hızlı ve kesintisiz iletişime ihtiyaç duyulmaktadır. Dijital iletişim ağları ise bu etkileşimin gerçekleşmesi bazında hesaplı, hızlı ve kolay bir seçenek olarak tercih edilmektedir (Öztürk Dağabakan 2017:122).

Dijital iletişim biçimlerinin gündelik hayatımızda giderek artan bir şekilde yayılması ve daha sık kullanılmasıyla sosyal etkileşim açısından yüz yüze iletişim bağlamından uzaklaşan yeni alanlar karşımıza çıkmaktadır.

Dijital iletişim araçları ve sosyal ağlar temel üretim ve kabul koşulları açısından yüz yüze etkileşimden farklı olsa da yüz yüze iletişimde olduğu gibi bu tür uygulamalarda da sosyal etkileşim normları çoğunlukla yer bulmaktadır.

Çalışmanın uygulama kısmını oluşturan bu bölümde dijital medyadan, çeşitli sosyal ağlardan, internet taramalarından elde edilen veriler kadınların kullandığı hitap ifadeleri bağlamında irdelenerek incelenecektir. Aynı zamanda Berlin'de Humboldt Üniversitesi'nde ve Erzurum'da Atatürk Üniversitesi'nde yapılmış olan iki anket de veri olarak kullanılacaktır. Söz konusu anketler Atatürk Üniversitesi ve Humboldt Üniversitesi'nin yer aldığı Uluslararası İş Birliği Projesi kapsamında her iki üniversitenin Alman Dili ve Edebiyat1 Bölümleri öğrencilerinden her bir bölümden 15, toplamda 30 kadın öğrencinin katılımı ile gerçekleştirilen bir araştırmadır. $\mathrm{Bu}$ çalışma yukarda değinilen projenin bir bölümünü oluşturmaktadır.

Dijital iletişimde kullanılan Chat, SMS, WhatsApp, Facebook, Twitter veya Instagram gibi yazı tabanlı iletişim araçları ve sosyal ağlar günümüzde bireylerin tercih ettiği iletişim unsurlarını oluşturmaktadır. Türkiye'de ve Almanya' daki kadınlar da genel olarak iletişimlerinde söz konusu dijital platformları kullanmaktadırlar. Kadınları iletişimleri de toplumdaki diğer bireyler gibi genel olarak sosyal medyada büyük oranda yakın arkadaşlar arasında sohbet tarzında ve bilgi alışverişi şeklinde gerçekleştirmektedir. Her türlü etkileşimde iletişime başlarken ilk etapta iletişim kurulacak olan kişiye bir hitap gerekmektedir. Hitaplar konusunda her iki dilde de farklılıklar ve çoğunlukla benzer özellikler görülmektedir. Kadınların kullandıkları hitap ifadeleri erkeklerin kullandıklarından farklı olmakla beraber verilerin değerlendirilmesi bağlamında öncelikle bu sözcükleri (samimiyet ve resmiyet derecesi olarak) kimlere nasıl hitap edildiğine göre aile arasında kullanılan hitaplar, iş, resmi ortamlar vs. arkadaşlara kullanılan hitaplar, yakın arkadaşlara kullanılan hitaplar, eş veya sevgiliye karşı kullanılan hitaplar olarak sınıflandırılabilir. Söz konusu sınıflandırma yapılan anketlerde de bu şekilde ele alınmıştır. Anket soruları, aile bireylerine, yakın ve resmi arkadaşlara, eş veya sevgiliye karşı kullanılan hitap ifadelerinin hangi şekilde tanımlandığını içermektedir. Anketlerde sebep sorulmamıştır. Anketler dışında gözlemler ve görüşmeler yoluyla da veri elde edilmiştir. Bununla beraber çeşitli dijital platformlardaki kullanımların aktarımı da birçok verinin elde edilmesini sağlamıştır. Bilindiği gibi dijital platformların birçoğunda serbest erişim bulunmaktadır. Bir dijital platforma üye olmak bu tür verilerin kolayca elde edilmesini sağlamaktadır. Yine internetteki çeşitli bloglardan 
veya buna benzer platformlardan da birçok veri elde edilmiştir. Toplanan veriler çok fazla olduğu için aşağıdaki tablolara tamamı yazılmamış, bu durum tablonun sonunda üç nokta işareti ile belirtilmiştir. Burada kullanılmayan verilerin başka bir çalışmada kullanılabileceği de öngörülmektedir.

\section{Aile Arasında Kullanılan Hitap İfadeleri}

Aile arasında kullanılan hitap ifadelerinin ele alındığı bu bölümde Türkçe ve Almancada kullanılan akrabalık isimleri değerlendirilmektedir. Her iki dil arasındaki görsel mukayeseyi kolaylaştıracağının düşünüldüğünden, veriler her bölümde öncelikle bir tablo içerisinde verilmiştir. Yukarda da bahsedildiği gibi toplanan verilerin çokluğundan bu durum tablonun sonunda üç nokta işareti ile belirtilmiştir.

\begin{tabular}{|l|l|}
\hline \multicolumn{2}{|c|}{ Aile Arasında Kullanılan Hitap İfadeleri } \\
\hline Türkçe & Almanca \\
\hline Abim & Bärchen \\
Ablam & Dädi \\
Ablişgo & Großmama \\
Angılı (aklı havada) & Großmutter \\
Anneciğim & Großpapa \\
Annem & Großpapi \\
Anniş & Großvater \\
Aslanım & Großvati \\
Babacığım & Hase \\
Babiş & Kusinchen \\
Bir Tanem & Mama \\
Cadı & Mutti \\
Canım & Mutter \\
Canımın İçi & Onkel \\
Ciğerim & Tante \\
Dedoş & Papa \\
Gençler & Vati \\
Halacığım & Vater \\
Halam & Maus \\
Kardeşim & Mäuschen \\
Kemçik (alt çenesi çıkık ve üst \\
çenesi içeriye çökmüş gibi duran, \\
dişleri üst üste gelmeyen) & Mausebärchen \\
Kemik Yığını & Opi \\
\hline
\end{tabular}




\begin{tabular}{|l|l|}
\hline Kızım & Turtle Taube \\
Kızlar & Süße \\
Kuzum & Schwesterchen \\
Lalık (hiçbir şey bilmeyen) & Schatz \\
Paşam & Schwesterlein \\
Prensesim & Bruderherz \\
Sarı (sarışın) & Spatz... \\
Teyzeciğim & \\
Teyzem.... & \\
\hline
\end{tabular}

Tablo 1: Aile Arasında Kullanılan Hitap İfadeleri

Yapılan araştırma sonucu aile arasında kullanılan birçok hitap ifadesi elde edilmiş bulunmaktadır. Bu hitap ifadelerinin çoğu her iki dilde de benzerlik göstermektedir. Aile arasında kullanılan hitap ifadeleri genellikle aile içerisinde sahip olunan akrabalık derecesinin dile getirilmesi şeklinde ortaya çıkmaktadır. Bu ifadeleri de iki grupta görebiliriz. Bunlardan Anne/Anniş, Baba/Babiş/Babişko, Anneanne, Babaanne, Dede/Dedoş, Abla, Abi, Dayı, Teyze, Hala, Amca sözcükleri özel isim olmadan tek başına kullanılmaktadır. Söz konusu hitap ifadeleri Almancada da kullanım açısından benzerlik göstermektedir. Mutter /Mutti /Mama, Papa/ Vater / Vati, Oma/Omi ve Opa/Opi, Tante /Onkel özel isim olmadan kullanılmaktadır. Aynı zamanda yakınlık ve uzaklık derecesine göre yani akrabalık bağının birinci derecede olmaması durumunda Teyze/Amca, Onkel/Tante, Abla/Abi gibi hitaplar Almancada da Türkçede olduğu gibi özel isme eşlik etmektedir (Onkel Hans/Tante Berta, Ayşe Teyze/Ali Amca, Sevda Abla/Mustafa Abi).

Aile içi hitaplarda her iki dilde de karşılaşılan bir başka unsur sevgi ifadelerinin kullanılmasıdır. Hitap edilen kişiye doğrudan ismi veya aile içerisinde taşıdığı akrabalık ifadesi ile değil, sevgi ifadeleri ile hitap edilmektedir. Canım, Canımın İçi, Bir Tanem, Prensesim, Abbişim, Anniş, Dedoş, Schatz, Süße, Papi, Dädi, Großpapi, Vati, Bruderherz... hitap sözcüklerinin her biri aşırı sevgi ifadesi barındırmaktadır. Abbişim, Anniş, Dedoş, Babiş gibi ifadelerde yer alan -iş ve -oş ekleri -cağım, -ciğim ekleri yerine kullanılan ve aşırı sevgi ifade eden, günlük dilde daha da sık kullanılan ekler olarak karşımıza çıkmaktadır. Hitaplardaki ses değişimini Almanca sözcüklerde de Papi, Mutti, Großpapi, Vati, Opi... şeklinde görmek mümkün. İletişim esnasında sevgi isimlerinin kullanılması, hitap eden kişi yani gönderen için sevgi ve yakınlığı ifade etmenin samimi bir yolu olarak tanımlanabilir. Abim, Ablam, Bir Tanem, Ciğerim... sözcüklerinde dikkatleri çeken -(i)m iyelik eki hitap edilen kişiye karşı duyulan sevgiyi dile getirmektedir, aynı zamanda bu sevgi içerisinde bir sahiplik vurgusu da bulunmaktadır. Yine Türkçede ve Almancada dikkatleri çeken bir diğer unsur küçültme eklerinin kullanımı olarak ortaya çıkmaktadır. Anneciğim, Babacığım, Kusinchen, Schwesterchen, Schwesterlein vb. hitap sözcüklerinde sevgi duygusu vurgulanmaktadır. 
Aslanım, Kuzum, Bärchen, Maus, Mäuschen, Mausebärchen, Zuckermaus, Spatz hitaplarında hayvan isimleri yer bulmaktadır. Türkçede aslan gücü, kuzu ise sevimliliği temsil eden ve çok kullanılan iki isimdir. Bu yüzden gerek konuşma dilinde gerekse dijital iletişimde bu tür hitaplara çok sık rastlanmaktadır. Aslan, Türk toplumunda erkeklere, kuzu ise çoğunlukla küçük çocuklara bir gönderge olarak kullanılan iki isimdir. Almancadaki hitap ifadelerinde çoğunlukla ayı ve fare sevgi ifadesi taşıyan isimler olarak vurgulanmaktadır. Burada da iki kültür arasındaki farkı görmek mümkündür. Türk toplumundaki kuzu anlamı Almancada fare sözcügünde, aslan ise ayı sözcüğünde yer bulmaktadır. Oysa Türkçede fare ve ayı sevgi ifadesi olarak değil de daha çok aşağılama belki de hakaret ifadesi olarak kullanılmaktadır. Burada değinilmesi gereken bir başka unsur da Türkçe hitap ifadelerinde sahip olunan akrabalık isminin hitap edilen kişiye yakıştırılmasıdır. Yani halacığım, teyzeciğim, teyzem, halam, annem, anneciğim gibi ifadeler hala ve teyzenin yeğenine, annenin çocuğuna karşı ifade ettiği bir sözcük olarak işlev görmektedir. Son birkaç seneden beri daha da yoğunlaşan bu tür seslenmeler dijital ortamda da yer bulmaktadır. Almancada böyle bir davranış bulunmamaktadır.

Listede yer alan Angılı (aklı havada), Kemçik (alt çenesi çıkık ve üst çenesi içeriye çökmüş gibi duran, dişleri üst üste gelmeyen), Kemik yığını, Lalık (hiçbir şey bilmeyen), Sarı (sarışın) hitap ifadeleri daha önce bahsedilmiş olan anket sonucunda elde edilen veriler arasında yer almaktadır. Bu hitaplar genelde çok karşılaşılan sözcükler olmamakla birlikte bazılarının anlamları da pek fazla bilinmemektedir. Anket katılımcısı tarafından "aklı havada" olarak açıklanan Angılı sözcüğü Türkiye Türkçesi A Sözlüğ̈̈ ’nde “1.Ünlü, tanınmış, namlı, şöhretli, soylu. 2. Saygın, ünlü.” (Türkiye Türkçesi Ağızlar1 Sözlügü: 25.10.2021) şeklinde tanımlanmaktadır. Aynı şekilde Lalık sözcüğü için de Türkiye Türkçesi A ̆ğzları Sözlüğü’nde anket katılımcısının açıklamış olduğu anlamdan farklı bir anlam verilmektedir. Anket katılımcısının "hiçbir şey bilmeyen" tanımıyla açıklamış olduğu Lalık sözcügünün Türkiye Türkçesi A ğızları Sözlüğü’ndeki karş1lı̆̆ "1. Aptal - Gemerek Sivas, 2. Peltek konuşan, sözü anlaş1lamayan - Koyulhisar, Şarkışla Sivas, 3. Tembel, kekeme, dilsiz.” (Türkiye Türkçesi Ağızları Sözlüğü: 25.10.2021) olarak açıklanmaktadır. Yine Kemçik ve Kemik Yığını hitapları da alışılagelmişin dışında bir özellik sergilemektedir. Bu hitaplar Türkiye'nin her yerinde kullanılan hitaplar olmamakla beraber özel gruplar içerisinde, kendi asıl anlamları haricinde kullanılan hitaplar olarak ortaya çıkmaktadır. Söz konusu hitaplar diğerlerinden farklı olarak olumsuz anlam iletmektedir ve hitap edilen kişiyi küçük düşürme, aşağılama anlamı ifade etmektedir. Bu hitaplara oranla daha anlaşılır olan Sarı sözcüğü hitap edilen kişinin fiziksel özellikleri bağlamında yakıştırma olarak tanımlanabilir. 


\section{Arkadaşlara (iş, resmi ortamlar vs.) kullanılan hitaplar}

Arkadaşlara karşı kullanılan hitapların ele alındığı bu bölümde iş ortamında daha doğrusu resmi ortamlarda arkadaşlara karşı kullanılan hitaplara değinilmektedir.

\begin{tabular}{|l|l|}
\hline \multicolumn{2}{|c|}{ Arkadaşlara (iş, resmi ortamlar vs.) kullanılan hitaplar } \\
\hline Türkçe & Almanca \\
\hline Abi & Frau \\
Arkada & Herr \\
Başkanım & Kollege \\
Bey & Kollegin \\
Canım & Liebe Frau X \\
Dostum & Liebe Kollegin \\
Hanım & Lieber Herr X \\
Hocam & Lieber Kollege \\
Kardeş & Sehr geehrte/r Frau/Herr... \\
Kardeşim & \\
Müdürüm & Teklifsiz grup hitaplarında: \\
Patron & „Hallo zusammen“ ya da „Liebe \\
Sayın & alle“... \\
Usta & \\
Yetkili ... & \\
\hline
\end{tabular}

Tablo 2: İş Arkadaşlarına kullanılan hitap ifadeleri

Arkadaşlara karşı kullanılan hitap ifadeleri kullanım ortamına göre farklılıklar göstermektedir. Bu bağlamda arkadaş hitaplarının iki grupta sınıflandırılması da uygun görülmektedir. Bu bölümde kadınların iş yerinde veya resmi ortamlarda arkadaşlarına karşı kullandığ hitaplar, bir sonraki bölümde ise daha samimi ortamlarda kullandıkları hitaplar ele alınacaktır. İş ortamı gibi daha resmiyet gerektiren koşullarda hitaplar da söz konusu ortamlara uyum sağlamak zorundadır. Günümüzde her iş yerinde iletişimin kolaylaştırılması bazında belli sosyal platform gruplarının kurulduğu görülmektedir. Örneğin bir iş yerinde bütün çalışanların içerisinde bulunduğu üst bir grup mevcutken, alt birimlerin her birinin kendine ait başka gruplarda bir araya geldiği görülmektedir. Bu örnek gerek Almanya'da gerekse Türkiye'de yapılan gözlemler sonucu belirlenmiş olmakla beraber, anket ve görüşmelerde de bunu desteklemektedir. Bu tür gruplarda da mutlaka grup içerisinde belli bir iş ortamı mesafesi sağlanmaktadır. Özelde farklı hitap edilen bir arkadaşa bu tür gruplar içerisinde daha resmi bir göndermede bulunmak gerekmektedir. Yine anket, görüşme ve gözlem sonuçları söz konusu durumun onaylamaktadır. İş arkadaşlarına hitaplarda mesleki unvan bazen kişi adına eşlik 
etmektedir. Hocam, Başkanım, Müdürüm, Usta vb. sözcükler bu şekilde kullanılabilen hitap ifadeleridir. Fatma Hocam, Ahmet Başkanım, Ayşe Müdürüm, Murat Usta gibi kullanımlar haricinde söz konusu hitaplar daha kısa olsun diye isim olmadan da kullanılabilmektedir. Burada dikkat edilmesi gereken bir unsur, hitapların bazılarının iyelik eki ile kullanılmasıdır. Bu tür kullanımlarda sahiplenişle birlikte bir saygı anlamı da vurgulanmaktadır. Türk toplumunda yüz yüze iletişimde ve her ortamda çok fazla rastlanan bu durum dijital platformlarda da göze çarpmaktadır. İş ortamında daha resmi bir durumda Hanım, Bey, Sayın ifadeleri mesafeli bir anlam yansitmaktadır. Bu hitap ifadeleri de yine isme eşlik eden sözcükler olarak kullanılmaktadır. Türkçedeki bu ifadeler gibi Almancadaki Frau, Herr, Kollege, Kollegin hitap ifadeleri kullanılmaktadır. Almancada da bu sözcüklere kişi adları eşlik etmektedir. Almancadaki Liebe Frau X, Liebe Kollegin, Lieber Herr X, Lieber Kollege hitapları Sehr geehrte/r Frau/Herr X hitabiyla mukayese edildiğinde daha samimi bir anlam taşımaktadır. Bu hitaplara çoğunlukla soyadı eşlik etmektedir. Almancadaki bu durum Türkçeden farklı bir kullanım göstermektedir. Türkçede gerek resmi hitaplarda gerekse teklifsiz konuşmada soyadı kullanımı bulunmamaktadır. Almancada soyadının kullanılması resmiyeti vurgulamaktadır. Abla, Dostum, Kardeş, Kardeşim, Canım gibi hitaplar iş yeri gibi ortamlarda daha samimi bir anlam vurgulamaktadır. Söz konusu ifadeler dijital ortamda iletişime başlarken ve iletişimi sürdürürken sık sık kullanılan hitap sözcükleridir. Teklifsiz grup hitaplarında Türkçede Arkadaşlar sözcüğü Almancada ise Hallo Zusammen veya Liebe Alle yapıları görülmektedir.

\section{Yakın arkadaşlara kullanılan hitaplar}

Arkadaşlara kullanılan hitap ifadelerinin ele alındığı bu bölümde yakın arkadaşlara kullanılan hitap ifadeleri samimiyet bağlamında incelenmektedir.

\begin{tabular}{|l|l|}
\hline \multicolumn{2}{|c|}{ Yakın Arkadaşlara kullanılan hitaplar } \\
\hline Türkçe & Almanca \\
\hline Ad & Ad \\
Adların kısaltılmış hali: Fatoş, & Allerliebster \\
Cemo... & Baby / Babe \\
Aşko(m) & Du \\
Kanka(m) & Du Morgenmuffel \\
Kardo & Hallo Du \\
Kanki & Hallo Alter \\
Mrb ... & Hallihallo \\
Meraba & Hallöchen \\
Panpa & Hey \\
Bebeğim & Hi \\
Bro & Moin \\
Knk & Tach \\
Karşim & Tach+isim \\
& Hase / Hasi / Häschen \\
\hline
\end{tabular}




\begin{tabular}{|l|l|}
\hline Canım & Schatz / Schatzi / Schätzchen \\
Fıstık & Maus / Mausi / Mäuschen... \\
Bebiş & \\
Bebişim & \\
Dostum & \\
Çiçeğim & \\
Aga & \\
Bacı(m) & \\
Kuzu(m) & \\
Cano & \\
Güzellik & \\
Kız & \\
Güzelim & \\
Tatlım ... & \\
\hline
\end{tabular}

Tablo 3: Yakın Arkadaşlara kullanılan hitap ifadeleri

Yakın arkadaşlar arasında kullanılan hitap ifadeleri resmi ortamlarda kullanılan hitap ifadelerinden farklılık göstermektedir. Kadınların yakın arkadaşları ile yazışırken, mesajlaşırken kullandıkları hitap ifadelerinin birçoğunu her iki dilde de sevgi sözcükleri oluşturmaktadır. Aşko(m), Bebeğim, Canım, Dostum, Çiçeğim, Kuzu(m), Fıstık, Bebiş, Bebişim, Güzelim, Tatlım, Güzellik, vb. sözcükler Türkçede yer bulmaktadır. Bunlardan Aşko(m), Fıstık, Bebiş, Bebişim gibi hitaplar özellikle daha genç kadınların hitap tercihi olarak ortaya çıkmaktadır. Arkadaşlara hitapta Almancada da sevgi sözcüklerinin kullanıldığı görülmektedir. Allerliebste/r, Baby / Babe, Hase / Hasi / Häschen, Spatz / Spatzi / Spätzchen, Schatz / Schatzi / Schätzchen, Maus / Mausi / Mäuschen gibi sevgi sözcükleri bu hitaplar arasında sınıflandırılabilir. Türkçe ve Almanca sevgi sözcükleri arasında dikkatleri çeken bir unsur, Almancada hayvan isimlerinin daha fazla kullanılmış olmasıdır. Yapılan araştırmada Türkçede Kuzum ifadesi veri olarak elde edilmiş, Almancada ise Hase / Hasi / Häschen, Spatz / Spatzi / Spätzchen, Maus / Mausi / Mäuschen ifadeleri görülmüştür. Yine daha önce de bahsedilmiş olduğu gibi Türkçede ve Almancada kullanılan hayvan isimleri farkl11ık göstermektedir. Türkçede kuzu benzetmesi yapılmakta, Almancada ise böyle bir durumda Türkçede pek fazla karşılaşamayacağımız tavşan, serçe, fare ifadeleri yer bulmaktadir.

Arkadaşlara hitap bağlamında elde edilen veriler olarak Türkçede Aga, Bacı(m), Cano, Kız, Karşim, Kanka(m), Kardo, Kanki, Panpa, Bro, Knk, Mrb, Meraba vb., Almancada ise Du, Du Morgenmuffel, Hallo Du, Hallo Alter, Hallihallo, Hallöchen, Hey, Hi, Moin, Tach+isim sözcükleri yer bulmaktadır. Bu hitaplarda en fazla dikkatleri çeken sözcüklerin farklı şekillerde kullanılmasıdır. Sözcüklerin farklı ifadeleri gerek Almancada gerekse Türkçede ses değişimi, ses ve hece eklemeleri, ses düşmesi, kısaltmalar vb. şekilde gerçekleşmektedir. Bu tür değişimler yazı dilinin konuşma diline uyarlanması, dilde ekonomi arayışı ve kullanıcıların tarz oluşturma beklentilerine bir karşılık olarak düşünülebilir (Dağabakan 2017: 122). Almancada Türkçeden farklı olarak değinilmesi gereken bir başka unsur ise hitap yerine selam sözcüklerinin daha sık kullanılmasıdır. Hallo Du, He Du, Hallo Alter, Hallihallo, Hallöchen, Hey, Hi, Moin, Tach+isim, Tach, 
Tag, Tagchen, şeklindeki selam sözcükleri Almancada çok fazla kullanılan ifadelerdir. Bu tür selam sözcükleri Türkçede Mrb ve Meraba şeklinde görülmektedir. Hitaplarda şahıs zamiri kullanımı Almancada göze çarpmaktadır. İkinci tekil şahıs Du Almancada selam sözcügünden sonra, tek başına veya ismin önüne getirilerek kullanılmaktadır. Türkçede şahıs zamirinin kullanıldığı bir durum gözlenmemiştir.

\section{Eş veya sevgiliye karşı kullanılan hitaplar}

Çalışmanın son bölümü olarak ele alınan bu bölümde kadınların eşlerine veya sevgililerine karşı kullandıkları hitap ifadeleri değerlendirilmektedir.

\begin{tabular}{|l|l|}
\hline \multicolumn{2}{|c|}{ Eş veya sevgiliye karşı kullanılan hitaplar } \\
\hline Türkçe & Almanca \\
\hline Aşkım & Schatz - Schatzi \\
Aşkitom & Liebling \\
Aşkitoşkom & Süßer \\
Ömrüm & Bärchen \\
Hayatım & Hase - Hasi \\
Sevgilim & Engel - Engelchen \\
Birtanem & Maus - Mausi \\
Biriciğim & Honey \\
Bey(im) & Baby \\
Yakı̧ıklım & Dicker \\
Canım & Traummann \\
Kocaçm & Mein Held \\
Kociş & Froschkönig \\
Kocişim & Liebes \\
Kocacığım & Mein Ein und Alles... \\
Gökyüzüm & \\
En Değerlim & \\
Tosunum & \\
Sevgilim & \\
Tatlım & \\
Balım & \\
Kalbim... & \\
\hline
\end{tabular}

Tablo 4: Eşe veya sevgiliye kullanılan hitap ifadeleri

Kadınların eşlerine veya sevgililerine kullandıkları hitap ifadeleri her iki dilde de çoğunlukla sevgi sözcüklerinden oluşmaktadır. İçerik olarak Türkçe ve Almancada kullanılan sevgi ifadeleri benzerlik göstermektedir. Aşkım ifadesinin türevleri şeklinde ortaya çıkan Aşkitom, Aşkitoşkom gibi hitaplar, yine Kocacığım sözcüğünün farklı kullanımları olan Kocacım, Kociş, Kocişim günümüzde yüz yüze iletişimde olduğu kadar dijital iletişimde de yoğun bir şekilde kullanılmaktadır. Türkçede çoğunlukla iyelik eki ile tanımlanmış bu sözcükler, seslenen kişinin hitap ettiği kişiye karşı sahiplenme duygusunun ve 
eşine karşı hissettiği yoğun sevginin göstergesi olarak karşımıza çıkmaktadır. Bu hitaplar haricince Ömrüm, Hayatım, Sevgilim, Bir Tanem, Biriciğim, Bey(im), Yakışıklım, Gökyüzüm, En Değerlim, Kalbim, Canım sözcüklerinde de aynı şekilde sahiplenme duygusunu görmek mümkündür. Almancada sahiplenme duygusunun öne çıktığı hitaplar olarak Mein Held, Mein Ein und Alles ifadeleri gözlenmektedir. Burada sahiplenme anlamı iyelik zamiri mein ile vurgulanmaktadır. Kadınların Almancada eşlerine karşı kullandıkları Froschkönig, Liebes, Schatz - Schatzi, Liebling, Süßer, Bärchen, Hase - Hasi, Engel Engelchen, Maus - Mausi, Baby, Dicker, Traummann ifadelerinde de sevgi duygusu vurgulanmaktadır. Engelchen ve Bärchen gibi sözcükler -chen küçültme ekinin kullanımı ile söz konusu ifadelerde sevgi vurgulanmaktadır. Aynı şekilde ayı, tavşan ve farenin dile getirildiği Bärchen, Hase - Hasi, Maus - Mausi hitap ifadeleri diğer sınıflandırmalarda olduğu gibi bu grupta da kendini göstermektedir. Türkçedeki Sevgilim, Tatlım, Balım, Bebişim hitaplarına denk gelen Liebling, Süßer, Honey, Baby Almancada da bulunmaktadır. Bununla beraber pek de alışılmadık olan, fiziki bir özellik vurgulayan Tosunum ifadesi Almancada Dicker olarak görülmektedir.

\section{Sonuç}

Türk ve Alman sosyal medyalarında kadınların hitap ifadelerinin ele alındığı bu çalışmada kadınların Türkçe ve Almancadaki dijital ortamda kullandıkları hitap ifadeleri her iki dil açısından karşılaştırılarak incelenmiştir.

Çalışmanın ilk bölümünü oluşturan kuramsal kısımda, hitapların tanımından yola çıkılarak konunun detayları ortaya konmuştur. Çalışmanın uygulama bölümünde, Türkçe ve Almancadaki sosyal medya söylemleri her iki dilde hitaplar açısından karşılaştırılarak incelenmiştir. Elde edilen bulgular kadınların iki dildeki hitap kullanımı bağlamında değerlendirilmiştir. Bu değerlendirme sonucunda Türkçe ve Almancada kadın dilinin hitaplar açısından ne tür bir kullanım alanının olduğu görülmüş, her iki dilde ne tür benzerlik ve farklılıkların gözlemlenebildiği sonucuna ulaşılmıştır.

Elde edilen bulgulardan yola çıkılarak özetlemek gerekirse, her iki dilde kadınların hitap kullanımlarının çoğunlukla benzerlikler gösterdiği tespit edilmiştir.

Hitap türlerinin dört başlık altında değerlendirilmiş olduğu çalışmada Ilk olarak aile içerisindeki hitapların ele alındığ 1 bölümde hitap ifadelerinin çoğunun her iki dilde de benzerlik gösterdiği görülmüştür. Aile arasında kullanılan hitap ifadeleri genellikle aile içerisinde sahip olunan akrabalık derecesinin dile getirilmesi şeklinde ortaya çıkmaktadır. Aile içi hitaplarda her iki dilde de karşılaşıllan bir başka unsur sevgi ifadelerinin kullanılmasıdır. Hitap edilen kişiye doğrudan ismi veya aile içerisinde taşıdığı akrabalık ifadesi ile değil, sevgi ifadeleri ile hitap edilmektedir. Aynı zamanda bu sevgi sözcüklerinin içerisinde bir sahiplik vurgusu da bulunmaktadır. Yine Türkçede ve Almancada dikkatleri çeken bir diğer unsur küçültme eklerinin sevgi ifadesi olarak kullanılmasıdır. Her iki dilde görülen bir benzerlik hayvan isimlerinin aile içinde sevgi ifadesi olarak kullanılmasından oluşmaktadır. Ancak hitap olarak kullanılan hayvan türlerinin Türkçe ve Almancada birbirinden tamamen farklı olduğu görülmüştür. Bununla 
beraber Türkçede, kişinin kendi sahip olduğu akrabalık derecesi ile karşıdaki kişiye hitap etme kullanımı Almancada bulunmamaktadır.

Resmi ortamlarda ve iş ortamında arkadaşlara hitap konusunun ele alındığı diğer bölümde iş arkadaşlarına hitaplarda mesleki unvanların kullanıldığı bazen de bu unvanların her iki dilde de kişi adına eşlik ettiği görülmektedir. İş ve resmi ortamlardaki hitaplarda her iki dilde de ortama göre resmi veya daha samimi bir hitap türünün tercih edildiği dikkati çekmektedir.

Yakın arkadaşlar arasında kullanılan hitap ifadelerinin incelendiği bir diğer bölümde söz konusu hitap ifadelerinin resmi ortamlarda kullanılan hitap ifadelerinden farklılık gösterdiği belirlenmiştir. Kadınların yakın arkadaşları ile yazışırken, mesajlaşırken kullandıkları hitap ifadelerinin birçoğunu yine her iki dilde de sevgi sözcükleri oluşturmaktadır. Aynı şekilde kadınların eşlerine veya sevgililerine kullandıkları hitap ifadeleri her iki dilde de çoğunlukla sevgi sözcüklerinden oluşmaktadır. Kadınların eşlerine kullandıkları sevgi ifadeleri Türkçe ve Almancada içerik olarak benzerlik göstermektedir.

Bununla beraber kadınların dijital etkileşimlerinde genel olarak selamlama kullanmadıkları, kullanılan selamlama ifadelerinin ise çoğunlukla kısaltmalar şeklinde ortaya çıktığı görülmüştür. Her iki dilde de özel isimler ile hitap biçimleri kadınların kullanım tercihlerini oluşturmaktadır. Sosyal statü ve samimiyet, resmiyet gibi etkenlerin hitap biçimlerinin kullanımını etkilediği inceleme esnasında belirlenen bir başka unsurdur.

Kadın dilinin, kadınların gönderen ve alıcı olarak hitap kullanımları bağlamında araştırıldığı yayınlardan Nilüfer Yıldırım'ın kaleme almış olduğu “Çağdaş Türk Yazı Dillerinde Kadına Yönelik Hitaplar” adlı makalede yazı dillerinde kadınlara yönelik hitap ifadeleri incelenmektedir (Yıldırım 2017). Marianne Wieczorek tarafından yazılmış olan "SMS-Kommunikation von Männern und Frauen am Beispiel von Begrüßungs- und Verabschiedungsformeln" adlı çalışmada SMS iletişiminde kadınların ve erkeklerin kullandığı selam ve veda ifadeleri kontrastif bir inceleme açısından değerlendirilmekte, makalede hitap ifadeleri ele alınmamaktadır (Wieczorek 2014). Turgay Han, Gencer Elkılıç, ve Nilüfer Aybirdi'nin birlikte yayınladıkları "Eşlerin Birbirlerine Sosyo-Edimsel Hitap Biçimleri Üzerine Tanımlayıcı Bir Çalışma” (Han, Elkılıç, Aybirdi 2019) başlıklı yazıda eşlerin birbirlerine hitapları edimbilimsel bir yaklaşım açısından değerlendirilmekte, söz konusu makalede kadınların eşlerine karşı kullandıkları hitap ifadelerine yöresel bazda değinilmektedir. Mustafa Aça'nın yazmış olduğu "Balıkesir Yöresinde Eşlerin Birbirlerine Hitap Biçimlerinin Bir Türü Üzerine” (Aça 2018) makalede ise yine bir önceki makalede olduğu gibi eşlerin birbirlerine karşı kullandıkları hitap ifadeleri yöresel bağlamda incelemektedir. Söz konusu çalışmalar bu çalışmadan farklılık göstermektedir. Çalışmanın konusunu oluşturan kadınların Türkçe ve Almanca dijital ortamlarda kullandığı hitapların, değerlendirilen makalelerin çoğunluğunda dijital içerik ve Türkçe Almanca karşılaştırma bağlamında yeterince araştırılmamış olduğu belirlenmiştir. Bu açıdan çalışmanın alandaki boşluğu dolduracağı, yeni araştırmalara yön vereceği düşünülmektedir. 


\section{Kaynaklar}

Aça, Mustafa (2018): Balıkesir Yöresinde Eşlerin Birbirlerine Hitap Biçimlerinin Bir Türü Üzerine, Karadeniz Araştırmaları Enstitüsü Dergisi, 4/5, 155-165.

Akalın, Şükrü Haluk (Ed.) (2011): Türk Dil Kurumu Yayınları Türkçe Sözlük,. 11. Baskı. Ankara: Türk Dil Kurumu.

Bußmann, Hadumod (2008): Lexikon der Sprachwissenschaft. Stuttgart: Alfred Kröner Verlag.

Ceylan, Tuncay (2012): Toplumsal Sistem Analizinde Toplumsal Statü ve Rol / Social Status and Role in the Analysis of Social System. Atatürk Üniversitesi Sosyal Bilimler Enstitüsü Dergisi. Say1 15 (1), 89-104.

Doğru, Fatih (2018): Seslenme Sözleri ve Genel Türkçe Sözlüklerdeki Görünümü. Eskişehir Osmangazi Üniversitesi Sosyal Bilimler Dergisi. Haziran. Say1 19(1), 135-150.

Han, Turgay/ Elkılıç, Gencer/ Aybirdi, Nilüfer (2019): Eşlerin Birbirlerine Sosyo-Edimsel Hitap Biçimleri Üzerine Tanımlayıcı Bir Çalışma, Millî Folklor 123. 2019, 166-176.

Johnen, Thomas (2019): Nominale Anredeformen in Fernsehwahlduellen: ein multilingualer Vergleich. Westsächsische Hochschule Zwickau, Fakultät Angewandte Sprachen und Interkulturelle Kommunikation.

Naber, Andreas (2015): Social Media. Definition, Rolle in der Kundenkommunikation und Macht der Nutzer. München GRIN Verlag.

Öztürk Dağabakan, Fatma (2016): Bir Toplumdilbilimsel Değişken Olarak Türkiye'de Kadın Dili Araştırmaları ve Görsel Medyada Kadın Dili. Diyalog. Sayı 1, 40-54.

Öztürk Dağabakan, Fatma (2017): Türkçe ve Almanca Sosyal Medyada Gençlik Dili. International Journal of Language Academy. Volume 5/4, 113-127.

Spillner, Bernd (2001): Die perfekte Anrede. Schriftlich und mündlich, formell und informell, national und international, Landsberg/ Lech: Verlag Moderne Industrie.

Spillner, Bernd (2014): Anrede und Grußformen im Deutschen. Zeitschrift des Verbandes Polnischer Germanisten. Issue 2, 173-187.

Türkiye Türkçesi Ağıları Sözlüğü, https://sozce.com/nedir/16154-angili (Erişim Tarihi: 25.10.2021).

Türkiye Türkçesi Ağızları Sözlüğü, https://sozce.com/nedir/215031-lalik (Erişim Tarihi: 25.10.2021).

Wieczorek, Marianne (2014): SMS-Kommunikation von Männern und Frauen am Beispiel von Begrüßungs- und Verabschiedungsformeln- Zur (Ir-)Relevanz des Zusammenhangs von Sprache und Geschlecht König, K., Bahlo, N. (2014): SMS, WhatsApp \& Co. Gattungsanalytische, kontrastive und variationslinguistische Perspektiven zur Analyse mobiler Kommunikation. Wissenschaftliche Schriften der WWU Münster, 173-192.

Yıldırım, Nilüfer (2017): Çağdaş Türk Yazı Dillerinde Kadına Yönelik Hitaplar. Uluslararası Türk Lehçe Araştırmaları Dergisi (TÜRKLAD). Cilt 1. Sayı 1, 123-137. 